Copyright by the Ecological Society of America. Paul L. Angermeier and Matthew R. Winston 1998. LOCAL VS. REGIONAL INFLUENCES ON LOCAL DIVERSITY IN STREAM FISH COMMUNITIES OF VIRGINIA. Ecology 79:911-927. http://

dx.doi.org/10.1890/0012-9658(1998)079[0911:LVRIOL]2.0.CO;2

Ecology, 79(3), 1998, pp. 911-927

(C) 1998 by the Ecological Society of America

\title{
LOCAL VS. REGIONAL INFLUENCES ON LOCAL DIVERSITY IN STREAM FISH COMMUNITIES OF VIRGINIA
}

\author{
Paul L. Angermeier ${ }^{1}$ and Matthew R. Winston 2,3 \\ ${ }^{1}$ United States Geological Survey, Virginia Cooperative Fish and Wildlife Research Unit, \\ Virginia Polytechnic Institute and State University, Blacksburg, Virginia 24061-0321 USA \\ ${ }^{2}$ Department of Fisheries and Wildlife Sciences, Virginia Polytechnic Institute and State University, \\ Blacksburg, Virginia 24061-0321 USA
}

\begin{abstract}
Local species richness is a function of many factors operating at multiple spatial and temporal scales. We examined stream fish communities from regions throughout Virginia to assess (1) the relative influence of local vs. regional factors on local species richness, (2) evidence for community saturation, and (3) scale dependency of regional influences. We defined regions at four spatial scales: major drainages, drainage-physiography units, hydrologic-physiography units, and sites. We used multiple regression to identify key correlates of local native and introduced diversity for each regional scale. Both local (e.g., microhabitat diversity) and regional (e.g., species richness) factors were correlated with local diversity; regional diversity was the most consistent correlate. Plots of local vs. regional native diversity were asymptotic for the three largest regional definitions, thereby suggesting community saturation. However, analogous plots for introduced species were not asymptotic; local introduced diversity was a linear function of regional introduced diversity. Introduced populations were pervasive, but less abundant locally than native populations, thereby suggesting that native species are better adapted. Overall, stream fish communities in Virginia appeared to be neither completely saturated nor freely invadable.

The ability of regression models and particular independent variables to account for variation in local diversity changed considerably with regional scale. Most regional correlates of local diversity were scale dependent. The concept of hierarchical environmental filters provides a useful framework for integrating the multiple scales over which ecological processes organize communities. Retrospective analyses of the impacts of introduced species on native communities provide some insight regarding community saturation, but conclusive evidence must await studies that couple comparative and experimental approaches. Clear interpretation of regional influences on local diversity will require careful definition of regions. Comparative analyses at multiple regional scales may be the most insightful approach to understanding the complete array of processes that organize communities.
\end{abstract}

Key words: community saturation; diversity relationships; environmental filters; fish, native vs. introduced species; introduced species; local vs. regional correlates of local diversity; regions, how to define; species diversity, local vs. regional; stream-fish communities; Virginia (USA) streams and fish communities.

\section{INTRODUCTION}

A central question in community ecology is "How is the number of locally occurring species regulated?" The emerging paradigm to explain local diversity is based on a hierarchical framework of multiple spatiotemporal scales, each with a suite of physical and biotic factors that can limit diversity (Menge and Olson 1990, Ricklefs and Schluter 1993a). Thus, answers to the question above often are framed in the context of local vs. regional or contemporary vs. historical influences. Complete answers must address the relative importance of large-scale processes (e.g., speciation, dispersal), which generally determine the species available to oc-

Manuscript received 30 May 1996; revised 14 April 1997; accepted 1 May 1997; final version received 22 May 1997.

${ }^{3}$ Present address: Missouri Department of Conservation, 1110 South College Drive, Columbia, Missouri 65201 USA. cur locally, and small-scale processes (e.g., competition, disturbance), which generally limit the number of species that actually occur locally (Ricklefs 1987, Brooks and McLennan 1993).

Prior to the paradigm just described, local, contemporary processes, especially biotic interactions, were assumed to dominate community assembly and organization. Because community structure was viewed as largely a product of the local environment, local diversity was expected to be strongly correlated with local physical and biotic features (Schluter and Ricklefs 1993). Furthermore, if interspecific competition was a predominant process, local diversity was expected to be near saturation, and distant communities in similar habitats were expected to have similar numbers of species (Schluter and Ricklefs 1993). Much of the recent debate on the relative importance of local vs. regional 
regulation of local diversity has focused on the latter two hypotheses.

Direct experimental tests of community saturation are desirable but typically infeasible due to logistic and ethical constraints. However, if sequences of community assembly could be observed, we would expect a saturated community to resist invasion, and species additions generally to be balanced by losses. Theoretical models suggest that saturation is a reasonably likely outcome of community assembly. For example, communities may become less invadable as the number (Case 1991) or connectance (Pimm 1989) of local species increases.

The use of comparisons provides an alternative to experimentation in empirical studies of community saturation. An important limitation of comparative approaches is that although patterns may be "explained" in a statistical sense, they generally cannot be explained mechanistically (i.e., cause-effect relationships are not identified). Most tests of community saturation have been based on a posteriori statistical inferences by comparing samples of communities from a series of regions with species pools of different sizes (Cornell 1993). Plots of local vs. regional species richness typically exhibit either a "proportional" or "asymptotic" pattern. In the proportional pattern local richness increases linearly with regional richness, but in the asymptotic pattern local richness increases with regional richness at a decreasing rate (i.e., local richness approaches or reaches an asymptote). The proportional pattern indicates an unsaturated community; the asymptotic pattern indicates potential saturation. However, other circumstances such as high regional heterogeneity or high rates of local extinction also may produce an asymptotic pattern (Cornell 1993), and the two patterns are distinguishable only if wide ranges of regional diversity are examined. Moreover, modest rates of disturbance can produce indistinguishable empirical relationships between local and regional diversity under very different levels of interspecific competition (Caswell and Cohen 1993). Given the inherent variation in estimates of local and regional diversity and the indirectness of available approaches, it is not surprising that few unambiguous tests of saturation have been reported (Cornell 1993).

Fish communities in small streams offer excellent opportunities to examine the relative influence of local and regional factors on local species diversity. Streamfish communities occur in a wide variety of landscapes and climates (i.e., many regions) with highly variable evolutionary histories. For North American fishes, geographic distributions (including native vs. introduced range) and taxonomy of species are well known (Lee et al. 1980, Hocutt and Wiley 1986, Mayden 1992), and there has been considerable study of important correlates of regional and local diversity. Finally, sampling technology allows accurate characterization of the species composition in a wide range of stream habitats.
The number of fish species occurring in stream communities is related to numerous local factors, many of which are correlated with each other or regional factors. For example, extreme water temperatures (high or low) often limit fish diversity, and spatially complex habitats typically support more species than simple habitats. Intense competition (e.g., Fausch and White 1981, Taylor 1996) or predation (e.g., Power et al. 1985, Gilliam et al. 1993) may often constrain local distribution of species. Human impacts on waters and watersheds typically reduce fish diversity, but some impacts (e.g., warming a coldwater stream) may actually increase local diversity. In some regions, local diversity may also reflect proximity to larger (more speciose) streams (Gorman 1986, Osborne and Wiley 1992) or to other sources of colonists (Angermeier and Schlosser 1989). Finally, some variation in estimates of local species richness may be a statistical artifact of population densities (Angermeier and Schlosser 1989, Angermeier and Smogor 1995).

The few studies examining the relationship between local and regional diversity for stream fishes suggest strong regional influences, which often reflect zoogeographic history. For example, communities in low-elevation streams of eastern North America, which has a relatively diverse fauna, are more speciose than those in Europe or western North America, where the faunas are relatively depauperate (Mahon 1984, Moyle and Herbold 1987). Plots of local vs. regional diversity of fishes in West African rivers show a linear relationship, thereby suggesting strong regional effects (Hugueny and Paugy 1995). However, key shortcomings of these studies are the small numbers of regions and questionable definitions of regional species pools (see Defining regions, below). Some studies of regional influences on local fish diversity in lakes suggest little regional control (Jackson and Harvey 1989, Tonn et al. 1990), but others have documented regional (Griffiths 1997) and historical (Hinch et al. 1991) effects.

A major constraint on studying effects of regional diversity on local diversity is the general infeasibility of conducting controlled experiments. For fish communities, however, many uncontrolled manipulations have occurred in the form of species introductions outside native geographic ranges. Introductions provide opportunities to examine responses of local communities to invasion and to draw inferences about community saturation. Although introduced fishes are widely thought to be key agents of endangerment for native fishes (Williams et al. 1989, Flather et al. 1994) there are few focused studies that clearly compare the community structure of pre- and post-introduction scenarios. Success rates for introducing stream fishes, which should be inversely related to community saturation, are highly variable among systems (Ross 1991), but some patterns are consistent with expectations for saturated communities. For example, successful introductions usually are followed by declines 
in native populations (Ross 1991), and introductions are more likely to succeed in systems that are naturally depauperate or highly modified by human impacts (Herbold and Moyle 1986, Ross 1991, Courtenay and Moyle 1996).

Closer examination of relationships between native and introduced populations may help reveal the factors regulating local diversity. If communities typically are saturated, we would expect local establishment of introduced populations to be uncommon, especially where native diversity is high, and establishment should precipitate loss of native species. Important limitations for testing these hypotheses are that frequencies of invasion "attempts" and pre-invasion community structure in real systems are largely unknown. Community saturation implies a coevolved assembly of populations. If saturation is common, we also would expect coevolved native species to be better adapted for using available resources than introduced species (not coevolved). Thus, native populations should enjoy greater success (e.g., be more abundant) than introduced populations. In contrast, if communities are not saturated, we would expect local species composition to mimic random draws from regional species pools, and native populations should be no more successful than introduced populations.

\section{Defining regions}

Understanding the role of regional influences in community organization requires careful definition of regional boundaries. An ideal region is environmentally homogeneous, equally accessible throughout to all species in the region, and has ecologically relevant boundaries. Each region in an ideal array of regions shares similar environmental conditions and history, but differs in species richness. The departure of real arrays of regions from these criteria has confounded many previous analyses of regional influences on local diversity. The designation of islands or continents as regions is common (see examples in Ricklefs and Schluter $1993 b$ ) but often inappropriate because large heterogeneous areas usually include many species not adapted for the habitat type being studied (Cornell 1993) or unable to disperse to it (Simberloff 1970). Both constraints induce spurious asymptotes in plots of local vs. regional diversity. Moreover, geographically distant areas typically experience different climates and share little phylogenetic history (Brooks and McLennan 1993); both climate and phylogeny strongly affect regional diversity. Thus, in intercontinental comparisons of communities, similarities (or differences) due to active ecological processes may not be distinguishable from those due to disparate histories.

Comparisons across intra-continental regions are more likely to provide insight regarding regional influences on local diversity. Such regions must be different enough evolutionarily to have different species pools, but similar enough ecologically to share habitat types and related species. For stream fishes, which generally cannot disperse across drainage boundaries, drainage basins represent objectively defined, ecologically relevant regions within continents. Each major drainage basin in North America supports a distinctive fish fauna (see chapters in Hocutt and Wiley [1986]), although adjacent drainages typically share many species and exhibit complementary distributions of closely related species. Atlantic-slope drainages typically support fewer species than drainages in the massive, speciose Mississippi River basin.

Regions for fishes might also be defined by physiographic provinces (Fenneman 1946) because different physiographies (even within a drainage) often support distinctive fish faunas (Hocutt and Wiley 1986, Jenkins and Burkhead 1994). Physiographic provinces also are appealing as regional units because of the strong influences of landform on habitat quality, disturbance patterns, and organism dispersal (Swanson et al. 1988).

Regions may be defined reasonably over a wide range of spatial scales (e.g., major basins to small watersheds for aquatic systems). However, the sensitivity of relationships between local and regional diversity to regional definition is poorly understood and largely unstudied. As a given area is divided into progressively smaller regions, relationships between local diversity and regional descriptors are likely to change in response to reduced variance at smaller scales (Wiens 1989). For example, we would expect some regional factors to be correlated with local diversity over only a limited range of regional scales. We would also expect the average historical difference among regions to diminish, and the distinction between local and regional factors to blur for small regions.

\section{Hypotheses and predictions}

In this paper we use samples of stream-fish communities from arrays of regions in Virginia to examine the relationship between local and regional species richness. Our primary objectives are (1) to partition the variation in local diversity into local vs. regional influence; (2) to assess the evidence for saturation of local communities; and (3) to examine the scale dependency of regional influences on local diversity. We focus our analyses on three hypotheses and their attendant predictions. The hypothesis that local factors regulate local diversity generates Prediction 1: local factors are better predictors of local diversity than are regional factors. The hypothesis that communities are saturated generates Prediction 2: plots of local vs. regional diversity exhibit an asymptotic pattern; Prediction 3: native communities resist invasion by introduced species; Prediction 4: invasion success is inversely related to local native diversity; and Prediction 5: native populations are more successful than introduced populations. The hypothesis that regional effects on local diversity are scale dependent generates Prediction 6: re- 
lationships between local diversity and regional factors vary with regional scale.

\section{Methods \\ Site selection}

Single sample sites on each of 61 streams were selected from a database of $>320$ sites sampled during a statewide stream survey conducted from 1987 to 1990 (P. L. Angermeier and R. A. Smogor, unpublished report [1992] to Virginia Department of Game and Inland Fisheries, Richmond, Virginia, USA). To minimize variation in local diversity due to variation in stream size, only sites on third-, fourth-, and fifth-order streams were used. Site selection was based on sampling adequacy (see below) and minimal human impact. Human impact at sites was assessed on the basis of land use in the watershed and along the riparian zone, presence of industrial (e.g., coal dumps) and municipal (e.g., water treatment plants) facilities in the watershed, condition of the stream bank and channel, and proximity to major impoundments. All sites were at least $1.5 \mathrm{~km}$ from any impoundment and at least $4 \mathrm{~km}$ from a major impoundment. Selected sites were not pristine, but were judged to have experienced minimal impact.

\section{Fish and habitat sampling}

At each site we used an electric seine (Angermeier et al. 1991) to collect fish from individual habitat units (e.g., riffles, pools). The upstream and downstream ends of each habitat unit, which coincided with obvious discontinuities in depth, current, or bottom type, typically were blocked with nets during sampling. Three to five persons used dip nets to retrieve all stunned fish observed. Most habitat units were electrofished twice in the upstream direction. The sampling crews attempted to include all types of habitat units observed at a site in the sample. Most fish were identified to species in the field, then released. Problematic specimens were identified in the laboratory. Sites were not studied in sufficient detail to ascertain whether the collected fish represented viable populations. We assumed that all individuals were from established populations.

Detailed habitat characterizations were made at about two thirds of the sites (Appendix). We used methods similar to Angermeier and Schlosser (1989) to characterize the structure of each habitat unit at these sites. At each of a series of regularly spaced points along a series of regularly spaced transects across the stream channel (i.e., at points in a grid) water depth was measured and bottom type and cover availability were estimated. The length and width of each habitat unit were also measured. Depth was categorized into decimeter intervals (e.g., 1-9 cm, 10-19 cm, 20-29 $\mathrm{cm})$. Bottom type was categorized as 1 of 10 mineral substrates (e.g., clay, sand, cobble, bedrock) and 1 of 3 bottom covers (none, debris, live vegetation). Cover availability for fish was categorized as present (e.g.,
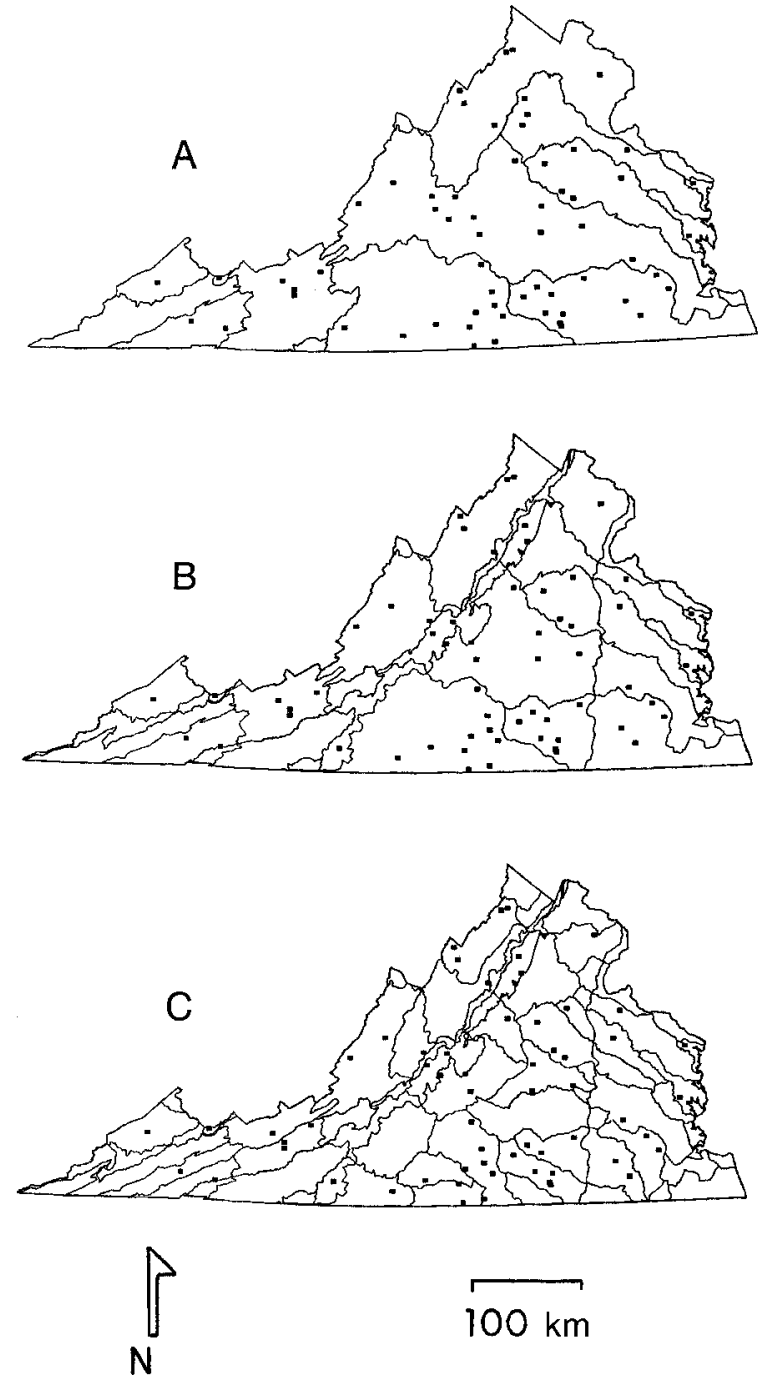

FIG. 1. Maps of Virginia showing the 61 sample-site locations (ם) and three spatial definitions of "region" used to analyze fish species richness. (A) Boundaries of 13 drainage basins (i.e., D regions); (B) boundaries of five physiographic provinces superimposed over (A) (i.e., DP regions); (C) boundaries of 43 hydrologic units superimposed over (B) (i.e., HP regions).

undercut banks, logs, boulders) or absent. Each unique combination of depth interval, bottom type, and cover availability was considered a microhabitat type; the number of types represented locally was tallied as a measure of habitat complexity. Hereafter we refer to the data set including all 61 sites as the "full" data set and to the the data set including only the 40 sites with detailed habitat data as the "partial" data set.

\section{Regional and local definitions}

We used four spatial definitions of "region;" we repeated analyses of local vs. regional effects on local diversity for each definition. The largest regions were defined by drainage basins (D regions; Fig. 1A). The 
second-largest regions (DP regions) were defined by dividing drainages into regions containing one of the five physiographic provinces represented in Virginia (Coastal Plain, Piedmont, Blue Ridge, Valley and Ridge, and Appalachian Plateau; Fig. 1B). The thirdlargest regions (HP regions) were defined by singlephysiography portions of the cataloging units (i.e., subdrainages) depicted on the Hydrologic Unit Map of Virginia (USGS 1980; Fig. 1C). The "local" spatial scale for each of these regional definitions (D, DP, and HP) was defined by individual sample sites.

Individual sample sites also defined the smallest regions ( $\mathrm{S}$ regions). Only those sites where three or more habitat units were sampled were used as regions. The local spatial scale for $\mathrm{S}$ regions was defined by individual pools, which were common types of habitat units in all physiographies. An additional regional definition, intermediate in scale between HP and S regions, would have been desirable, but our database was inadequate to provide reliable estimates of regional diversity at such a scale.

Lists of fish species occurring in D, DP, and HP regions were compiled from a comprehensive statewide data base of $>3200$ collections made since 1960 (P. L. Angermeier and R. A. Smogor, unpublished report [1992] to Virginia Department of Game and Inland Fisheries). This database included the 61 collections we used to estimate local diversity. To avoid inflating the regional species pools, only collections from third-, fourth-, and fifth-order streams were included in the compilations. Compilations included 173 (82\%) of the 211 freshwater fish species known from Virginia; our 61 collections included 112 species.

\section{Sampling adequacy}

Estimates of species richness for any locality or region are sensitive to sampling effort. Thus, accurate interpretations of species-richness patterns require adequate sampling effort at both local and regional scales. The number of fish species collected at a site may be influenced strongly by sampling efficiency and the amount of habitat sampled. Our electrofishing protocol is highly effective at capturing a wide variety of fishes in small streams (Bayley et al. 1989, Angermeier et al. 1991). Sample sites were 72-198 m long; relatively long reaches were sampled in large streams. Lengths of sample sites were $\geq 10$ times the average width, and usually $>16$ times that width. In Virginia, sample reaches $\geq 10$ stream-widths long typically yield 50 $80 \%$ of the species observed from reaches 7 times that long (Angermeier and Smogor 1995). Although species richness at sites often may have been underestimated, we judged the estimates to be adequate for analyses herein because variation in sampling effort among sites was distributed uniformly among regions. We also included measures of sampling effort as variables in multiple-regression models constructed to explain the variance in species richness (Table 1). These models enable
TABLE 1. Names and descriptions of independent variables used in regression models to predict local fish species richness in streams in Virginia (USA). Different-sized regions were used: $\mathrm{D}=$ drainage basins; $\mathrm{DP}=$ physiographic provinces within drainages; HP $=$ physiographic provinces within hydrologic units.

\begin{tabular}{ll}
\hline \hline \multicolumn{1}{c}{ Variable } & \multicolumn{1}{c}{ Description } \\
\hline SNAT & Number of native species at a site \\
PNAT & Number of native species in a pool \\
SINT & Number of introduced species at a site \\
PINT & Number of introduced species in a pool \\
SAREA & Area sampled at a site $\left(\mathrm{m}^{2}\right)$ \\
TOTFISH & Number of fish collected from a site \\
PFISH & Number of fish collected from a pool \\
WAREA & Watershed area above a site $\left(\mathrm{km}^{2}\right)$ \\
PAREA & Area of a pool $\left(\mathrm{m}^{2}\right)$ \\
HABTYPES & Number of habitat types at a site \\
MAXDEP & Maximum depth at a site $(\mathrm{cm})$ \\
PDEP & Maximum depth in a pool $(\mathrm{cm})$ \\
MICHAB & Number of microhabitat types at a site \\
PMICHAB & Number of microhabitat types in a pool \\
ELEV & Elevation at a site $(\mathrm{m})$ \\
RNAT & Number of native species in a D, DP, or \\
& HP region \\
RINT & Number of introduced species in a D, DP, \\
& or HP region \\
RNAT & Square of RNAT \\
SNAT ${ }^{2}$ & Square of SNAT \\
RDORD & Channel distance from site to larger-order \\
& stream (km) \\
RAREA & Area of a D, DP, or HP region $\left(\mathrm{km}{ }^{2}\right)$ \\
RNORD & Number of stream orders represented in a \\
& D, DP, or HP region \\
\hline
\end{tabular}

us to remove statistically the effects of sampling effort on estimates of local diversity (see Correlates of species richness, below).

The number of species recorded from a particular D, DP, or HP region (i.e., the regional species pool) could be influenced by the number of collections made there, especially when few collections have been made. Small regions were most likely to be represented by only a few collections in our comprehensive database. To ensure adequate collection effort in D, DP, and HP regions, we examined a plot of the number of collections vs. area for all HP regions. For each of the six HP regions with the fewest collections per unit area (mean number of collections per region $=9.5$ ), we conducted Monte Carlo simulations to test for sample adequacy. In each simulation, individual collections from the region were selected at random (with replacement), and a species list was compiled based on 1, 2, $3, \ldots, n$ collections; simulations were repeated 100 times. Plots of mean species richness vs. the number of collections from the region then were inspected for asymptotic relationships. Because all plots from simulations exhibited asymptotic patterns, the respective HP regions were judged to be sampled adequately, as were regions with more collections per unit area. Species richness of D, DP, and HP regions probably was often underestimated, but because the underestimation was distributed uniformly among regions, we judged 
sampling of regional species pools to be adequate for the analyses herein.

\section{Correlates of species richness}

We used 22 variables in multiple-regression analyses as potential correlates of local or regional species richness (Table 1). Variables were selected to emulate correlates of species richness demonstrated in the literature and to reflect data availability. We omitted several other potential correlates because preliminary analyses indicated that they had less explanatory ability than the 22 variables retained. Native vs. introduced status of each fish species followed Jenkins and Burkhead (1994). Numbers of fish collected from a site (TOTFISH) or from a pool (PFISH) were measures of sampling effort; site area (SAREA) served a similar role in analyses for D, DP, or HP regions. SAREA and pool area (PAREA) were estimated from field measurements of stream length and width. Areas of watersheds (WAREA) and D, DP, and HP regions (RAREA) were computed from boundaries digitized from USGS (United States Geological Survey) maps. We used three measures of in-stream habitat complexity: the number of habitat types at a site (HABTYPES), which included riffle, run, and pool; the maximum depth of each pool (PDEP) or site (MAXDEP); and the number of unique microhabitat types observed in each pool (PMICHAB) or site (MICHAB). Larger-scale measures of habitat complexity included the distance to a larger stream (RDORD) and the number of stream orders present in a D, DP, or HP region (RNORD). Stream order in Virginia ranges from one to eight. Site elevation (ELEV) provided a measure of thermal regime. Stream order and elevation were determined from USGS topographic maps (1:24000 scale).

Prior to regression analyses, we used the Box-Cox procedure (Krebs 1989) to transform variables. Because several variables remained non-normal after transformation, we performed analogous regression analyses based on data ranks (Iman and Conover 1979) to assess sensitivity of our results to non-normality. Although some differences in significance of individual variables occurred between analyses based on transformed data and analyses based on ranks, major correlates of local diversity and general patterns were similar. Thus, we believe findings based on the transformed data are robust and we present only those herein.

We developed regression models to explain local species richness (native or introduced) as a function of local and regional factors, where region was defined at four distinct spatial scales (one model per scale). To allow analysis of microhabitat data, which were available for only two thirds of our sites, we developed "full" and "partial" regression models for each regional scale. The full models contained 13 independent variables (but no microhabitat variable) for D, DP, and $\mathrm{HP}$ regions, and 10 independent variables (no microhabitat variable) for $\mathrm{S}$ regions. To allow comparisons of variable significance between full and partial models, we held the ratio of number of observations to number of independent variables $(N: I)$ constant. In particular, the initial list of independent variables used to analyze a partial data set included a microhabitat variable and all the variables used to analyze the corresponding full data set. The list of variables was then reduced by eliminating the independent variable accounting for the smallest Type II sum of squares (highest $P$ value). This process was repeated until $N: I$ for the partial model was as similar as possible to the $N$ : $I$ for the corresponding full model. All models for partial data sets included nine independent variables.

Interpretation of results from comparative ecological studies such as ours can be constrained by the intercorrelation of potentially important factors. For example, one could develop independent rationales for expecting relationships between local fish diversity and elevation or between diversity and stream size. But because elevation and stream size often are strongly negatively correlated in real landscapes, it may be difficult to sort out their relative influence on local diversity. We took three steps to ensure that intercorrelation among independent variables did not confound our regression results. First, no correlation coefficients among independent variables exceeded 0.90. Second, we tested for collinearity by calculating variance inflation factors (Shulman 1992); none was excessive $(>10)$. Finally, we used Type II sum of squares (ss) to measure the influence of each independent variable on local species richness. Type II ss estimates the additional variance in local diversity explained by each independent variable after all others have entered the regression model (i.e., the variance explained only by that variable). Although intercorrelation among independent variables cannot be removed entirely, we believe our statistical approach allows a reasonably clear interpretation of the relative influence of selected factors on local fish diversity.

\section{Testing predictions}

We tested Prediction 1 with multiple-regression models that included similar numbers of local and regional correlates of species richness as independent variables. The dependent variable in each model was either number of local native species or number of local introduced species. By integrating "effects" of all variables in a particular model, we could assess the relative strength of associations between local and regional factors and local diversity. We judged local factors to be better predictors of local diversity than regional factors if local factors explained more of the variance in local diversity, or if they more frequently or consistently explained significant proportions of the variance in local diversity.

We used two types of regression models to test Prediction 2. First, we tested Prediction 2 with the same models used to test Prediction 1. These models enabled 
TABLE 2. Summary of multiple-regression analyses of local species richness (SNAT or SINT) vs. selected independent variables at three spatial definitions of region. Table entries are regression coefficients.

\begin{tabular}{|c|c|c|c|c|c|c|}
\hline \multirow{2}{*}{$\begin{array}{l}\text { Independent } \\
\text { variable }\end{array}$} & \multicolumn{3}{|c|}{ Dependent variable $=$ SNAT } & \multicolumn{3}{|c|}{ Dependent variable $=$ SINT } \\
\hline & $\mathrm{D}$ & DP & HP & $\mathrm{D}$ & DP & HP \\
\hline SNAT L & $\cdots$ & $\cdots$ & 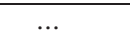 & 0.078 & 0.112 & 0.091 \\
\hline SINT L & 0.244 & 0.272 & 0.280 & $\ldots$ & $\ldots$ & $\ldots$ \\
\hline SAREA M & 0.498 & $0.578 *$ & 0.230 & $0.518 * *$ & $0.464 *$ & $0.514 * *$ \\
\hline TOTFISH M & $0.344 \dagger$ & $0.439 *$ & $0.369 *$ & -0.094 & -0.079 & -0.047 \\
\hline WAREA L & 0.015 & 0.068 & 0.092 & -0.092 & -0.067 & -0.035 \\
\hline HABTYPES L & 0.104 & 0.019 & 0.219 & $-0.242 \dagger$ & -0.172 & $-0.225 \dagger$ \\
\hline MAXDEP L & 0.026 & 0.022 & 0.026 & -0.004 & -0.001 & -0.008 \\
\hline ELEV L & -0.030 & -0.011 & -0.019 & 0.019 & 0.005 & 0.008 \\
\hline RNAT R & $0.0004 * *$ & $0.032 * *$ & $0.485 *$ & -0.0001 & -0.007 & -0.177 \\
\hline RINT R & $-0.126^{* *}$ & $-0.272 * *$ & $-0.246 \dagger$ & $0.084 * *$ & $0.228 * *$ & $0.259 * *$ \\
\hline RNAT $^{2}$ R & $-1.9 \times 10^{-8 *}$ & $-4.7 \times 10^{-5 * *}$ & $-0.007 \dagger$ & $4.3 \times 10^{-9}$ & $9.5 \times 10^{-6}$ & 0.003 \\
\hline RDORD R & 0.017 & -0.024 & -0.019 & -0.034 & -0.024 & -0.051 \\
\hline RAREA R & -0.0001 & 0.005 & -0.001 & 0.001 & 0.006 & 0.002 \\
\hline RNORD R & 0.001 & $-0.006 \dagger$ & $-0.001 \dagger$ & -0.001 & -0.0005 & $6.6 \times 10^{-5}$ \\
\hline \multicolumn{7}{|c|}{ Regression statistics } \\
\hline $\mathrm{L}: \mathrm{R}$ & $0: 3$ & $0: 3$ & $0: 1$ & $0: 1$ & $0: 1$ & $0: 1$ \\
\hline Model $R^{2}$ & $0.42 * *$ & $0.55 * *$ & $0.53 * *$ & $0.58 * *$ & $0.58 * *$ & $0.66 * *$ \\
\hline Intercept & -1.4 & $-4.68^{*}$ & $-4.99 \dagger$ & $-1.83 \dagger$ & -1.67 & -0.99 \\
\hline
\end{tabular}

Notes: Variable names and regional definitions are given in Table 1. Each variable's representation of a local (L), regional (R), or sampling (M) factor at the regional definitions shown is also given with the variable name. $N=61$ sites for each model. The variables' slopes (top block of entries) are based on Type II ss using transformed data. L:R represents the ratio of local to regional variables that achieved significance probabilities $<0.05$ for each model.

$\dagger P<0.10, * P<0.05, * * P<0.01$.

us to minimize potentially confounding influences of other independent variables and focus on the relationships between local and regional diversity. One of the regional variables in these models was the square of the number of native regional species $\left(\mathrm{RNAT}^{2}, \mathrm{SNAT}^{2}\right)$. We interpreted a significant negative slope for this variable to indicate an asymptotic relationship between local and regional species richness. Although this method does not identify an asymptote explicitly, it commonly is used to test for curvilinearity in plots of local vs. regional diversity (Cornell 1993). Such curvilinearity provides sufficient evidence to reject the proportional relationship between local and regional diversity. Second, we fitted simple regression models to plots of local vs. regional species richness. The plots and model coefficients enabled us to assess visually the shape and precision of the relationship between local and regional diversity.

We used occurrence of introduced species at sites to test Prediction 3. We judged native communities to resist invasion by introduced species if most sites lacked introduced species or if the local proportion of introduced species was less than the regional proportion. We reasoned that if native and introduced species were equally well adapted, the two proportions should be similar.

We used the multiple-regression models to test Prediction 4 . We judged invasion success to be inversely related to local diversity if, in regression models, the number of local introduced species either was negatively correlated with the number of local native species, or exhibited an asymptotic relationship with the number of regional native species. Asymptotes were assessed as for Prediction 2.

We used occurrence and abundances of introduced species at sites to test Prediction 5. First, we judged native populations to be more successful than introduced populations if, given similar-sized regional pools, local native diversity exceeded local introduced diversity. We also judged this prediction to be confirmed if native fishes were usually more abundant locally than introduced fishes. We compared abundances on the basis of total individuals and mean number of individuals per species. We compared abundances of native and introduced individuals based on the mean log-transformed number of individuals per species for both types of species at each of our 61 sites.

We tested Prediction 6 by comparing results of regression models for different regional scales. We judged this prediction to be confirmed if the variance in local diversity explained by models or by particular independent variables differed considerably among regional scales.

\section{RESULTS}

\section{Prediction 1. Local factors are better predictors of local diversity than are regional factors}

Results from multiple-regression models indicated that several local and regional factors were associated with local diversity; models typically accounted for $50-80 \%$ of the variation in local species richness (Tables 2, 3, 4, and 5). Regional variables typically outnumbered local variables as predictors of local native 
TABLE 3. Summary of multiple-regression analyses of local species richness (SNAT or SINT) vs. selected independent variables at three spatial definitions of region. Table entries are regression coefficients.

\begin{tabular}{|c|c|c|c|c|c|c|}
\hline \multirow{2}{*}{$\begin{array}{l}\text { Independent } \\
\text { variable }\end{array}$} & \multicolumn{3}{|c|}{ Dependent variable $=$ SNAT } & \multicolumn{3}{|c|}{ Dependent variable $=$ SINT } \\
\hline & $\mathrm{D}$ & DP & HP & $\mathrm{D}$ & $\mathrm{DP}$ & HP \\
\hline SNAT L & $\cdots$ & $\cdots$ & $\cdots$ & 0.230 & 0.530 & 0.290 \\
\hline SINT L & 0.221 & 0.299 & 0.204 & & $\ldots$ & \\
\hline SAREA M & -0.148 & $\cdots$ & $\cdots$ & $0.562 \dagger$ & 0.441 & $0.427 \dagger$ \\
\hline TOTFISH M & $0.205^{*}$ & $0.251 * *$ & $0.208 * *$ & -0.102 & -0.151 & $\ldots$ \\
\hline WAREA L & $\ldots$ & $\ldots$ & $\ldots$ & $\ldots$ & $\ldots$ & $\ldots$ \\
\hline HABTYPES L & -0.199 & -0.154 & 0.103 & -0.181 & $\cdots$ & -0.175 \\
\hline MAXDEP L & $\ldots$ & $\ldots$ & 0.005 & $\ldots$ & 0.006 & $\ldots$ \\
\hline MICHAB L & $0.971 * *$ & $0.853 * *$ & $0.709 *$ & $\ldots$ & -0.401 & $\ldots$ \\
\hline ELEV L & $\ldots$ & $\ldots$ & $\ldots$ & $0.036 \dagger$ & $\ldots$ & $\ldots$ \\
\hline RNAT R & $0.0003 *$ & $0.014 * *$ & $0.185 \dagger$ & $-5.7 \times 10^{-5}$ & $-0.015^{*}$ & -0.167 \\
\hline RINT R & $-0.069 * *$ & $-0.126^{*}$ & $-0.128 \dagger$ & $0.082 * *$ & $0.254 * *$ & $0.328 * *$ \\
\hline $\mathrm{RNAT}^{2} \mathrm{R}$ & $-3.7 \times 10^{-8 *}$ & $-1.7 \times 10^{-5 * *}$ & -0.003 & $\ldots$ & $1.7 \times 10^{-5 *}$ & 0.003 \\
\hline RDORD R & $\ldots$ & $\ldots$ & $\ldots$ & $\ldots$ & $\ldots$ & -0.081 \\
\hline RAREA R & $\ldots$ & $-0.007 \dagger$ & $\ldots$ & 0.005 & $0.009 \dagger$ & 0.002 \\
\hline RNORD R & $0.001 \dagger$ & -0.001 & $-3.4 \times 10^{-5}$ & -0.001 & $\cdots$ & $2.6 \times 10^{-5}$ \\
\hline \multicolumn{7}{|c|}{ Regression statistics } \\
\hline $\mathrm{L}: \mathrm{R}$ & $1: 3$ & $2: 3$ & $1: 0$ & $0: 1$ & $1: 3$ & $0: 1$ \\
\hline Model $R^{2}$ & $0.56 * *$ & $0.64 * *$ & $0.58 * *$ & $0.62 * *$ & $0.64 * *$ & $0.70 * *$ \\
\hline Intercept & -0.80 & $-2.35^{*}$ & $-2.70 \dagger$ & $-3.36 *$ & -0.72 & -1.53 \\
\hline
\end{tabular}

Notes: Variable names and regional definitions are given in Table 1; format as in Table 2. Analyses were performed on the "partial" data set $(N=40$ sites; see Methods: Fish and habitat sampling). Each model was reduced iteratively from the 14 independent variables listed to the nine variables with slope entries. Ellipses indicate that variables were not included in the final model.

$\dagger P<0.10, * P<0.05, * * P<0.01$.

diversity, especially for D (drainage basin) and DP (physiographic province within drainage basin) regions. Local native species richness was positively related to regional native species richness at all regional scales. This basic pattern was also apparent in simple regression models of local vs. regional diversity (Figs. 2 and 3). For D, DP, and HP (physiographic province within hydrologic unit) regions, RNAT was a significant $(P<0.05)$ predictor in five of the six regression models (Tables 2 and 3), and $\mathrm{SNAT}^{2}$ was a significant (positive) predictor in the partial data set for $\mathrm{S}$ (individual sample site) regions (Table 5) (see Table 1 for definitions of variables).

Regional introduced diversity (RINT, SINT) was a strong $(P<0.01)$ predictor of local introduced diversity in all eight models (Tables 2, 3, 4, and 5). Effects of sampling effort were also apparent, especially in the full data set, as indicated by the significance of localarea sampled (SAREA, PAREA). No other variables were significant predictors of local introduced diversity in more than one model.

Most variables that were significant $(P<0.05)$ in the full data set were also significant in the partial data set, and vice versa (Tables, 2, 3, 4, and 5). The most frequent shift in significance was for the variable localarea sampled (SAREA, PAREA), which lost significance in five of the eight comparisons between full and partial data sets. In the full data set no local variable was a significant $(P<0.05)$ predictor of local native diversity for D, DP, or HP regions (Table 2). In the partial data set microhabitat diversity (MICHAB) consistently predicted local native diversity at the three largest regional scales (Table 3), and PMICHAB was nearly significant $(P<0.10)$ in the model for $\mathrm{S}$ regions (Table 5). Furthermore, MICHAB accounted for a greater portion of the variance in local native diversity than did RNAT in D and HP regions (Table 3 ).

Overall, Prediction 1 was not confirmed. Regional predictors of local diversity typically outnumbered local predictors, especially for D and DP regions and for local introduced species richness. Regional diversity was the most consistent predictor of local diversity. Microhabitat diversity was the best predictor of local native diversity for large regional definitions, but was not useful for predicting local introduced diversity.

\section{Prediction 2. Plots of local vs. regional diversity exhibit an asymptotic pattern}

Results from multiple-regression models indicated that local native diversity was inversely related to $\mathrm{RNAT}^{2}$ for D and DP regions, and nearly so for HP regions, but not for $\mathrm{S}$ regions (Tables 2, 3, 4, and 5). These models never indicated an asymptotic relationship between local introduced diversity and RNAT ${ }^{2}$.

The most compelling evidence that local native diversity was related asymptotically to regional native diversity came from plots of the two variables. Simple linear-regression models indicated that they were positively correlated at all four spatial scales (Fig. 2). For D, DP, and HP regions, local communities typically included much less than half of the regional species, slopes were low $(<0.20)$, and intercepts were significantly $(P<0.05)$ positive. In contrast, $\sim 70 \%$ of the 
TABLE 4. Summary of multiple-regression analyses of local species richness (PNAT or PINT) vs. selected independent variables at the spatial definition of "site" as a region. Table entries are regression coefficients.

\begin{tabular}{lcc}
\hline \hline $\begin{array}{c}\text { Independent } \\
\text { variable }\end{array}$ & $\begin{array}{c}\text { Dependent } \\
\text { variable } \\
=\text { PNAT }\end{array}$ & $\begin{array}{c}\text { Dependent } \\
\text { variable } \\
=\text { PINT }\end{array}$ \\
\hline SNAT R & -0.189 & 0.327 \\
PNAT L & $\ldots$ & -0.035 \\
SINT R & 0.010 & $0.918^{* *}$ \\
PINT L & -0.243 & $\ldots$ \\
SAREA R & $-0.914 \dagger$ & -0.261 \\
PFISH M & $0.340^{* *}$ & -0.030 \\
PAREA L & $0.908^{*}$ & $0.309^{*}$ \\
HABTYPES R & 0.030 & -0.036 \\
PDEP L & -0.010 & -0.001 \\
ELEV R & -0.017 & 0.006 \\
SNAT & $0.090 \dagger$ & -0.026 \\
Regression statistics & & \\
L:R & $1: 0$ & $1: 1$ \\
Model $R^{2}$ & $0.80^{* *}$ & $0.76^{* *}$ \\
Intercept & 3.07 & -0.64
\end{tabular}

Notes: Variable names and regional definitions are given in Table 1. Each variables' representation of a local (L), regional (R), or sampling (M) factor is also given with the variable name. $N=62$ pools for each model. Variables' slopes (top block of entries) are based on Type II ss using transformed data. L:R is explained in Table 2. $\dagger P<0.10, * P<0.05$, ** $P<0.01$.

species in $\mathrm{S}$ regions typically occurred in individual pools, and the intercept was not different from zero.

Moreover, curvilinearity of the relationships for D, DP, and HP regions was underestimated by regression models because the models did not require the $y$ intercept to be $\leq 0$, a logical requisite. The lack of $\mathrm{D}$, DP, and HP regions with $<15$ native species makes extrapolation of the curves in Fig. 2 statistically unsupportable and highly speculative, but local diversity cannot logically exceed regional diversity. Thus, the complete forms of the curves in Fig. 2A, B, and C must bend to or below the origin for regions with $<15$ species. Such curves would clearly be asymptotic. In our plots, significantly positive intercepts provide further evidence for asymptotic relationships between local and regional diversity. Interestingly, the slope and intercept of the curve for S regions (Fig. 2D) are similar to those expected for extrapolated portions of the other curves in Fig. 2.

Plots of local introduced diversity vs. regional introduced diversity supported results from multiple regression. The two variables were positively correlated at all four regional scales (Fig. 3). Slopes were greater but intercepts were lower in plots of introduced diversity than in plots of native diversity (Figs. 2 and 3 ). No intercept in the regressions in Fig. 3 was different from zero. For D, DP, and HP regions, most localities supported fewer than half of the regional introduced species.

Overall, Prediction 2 was partially confirmed. Asymptotic relationships between local and regional di- versity were evident for native species in D, DP, and $\mathrm{HP}$ regions, but not for native species in $\mathrm{S}$ regions or for introduced species at any regional scale.

\section{Prediction 3. Native communities resist invasion by introduced species}

Introduced species were widespread; $92 \%$ of the sites had at least one species (median: two species). More introduced species occurred in larger regions (medians for HP, DP, and D regions: 5, 9, and 12 species, respectively). Introduced species were absent from four HP regions (9\%), but occurred in all DP and D regions.

For D and DP regions the local proportions of introduced species were smaller than regional proportions (sign test; $P<0.01$ ). That is, introduced species in large regions were underrepresented locally and patchily distributed within regions. In contrast, for HP and $\mathrm{S}$ regions the local proportions of introduced species were similar to regional proportions (sign test; $P$ $>0.10$ ), thereby suggesting that introduced species were distributed uniformly within small regions.

Overall, Prediction 3 was not confirmed. There was some evidence of resistance to invasion throughout large regions, but introduced species were pervasive. However, the ratio of successful to unsuccessful invasion attempts was unknown.

\section{Prediction 4. Invasion success is inversely related to local native diversity}

Local native diversity was never inversely related to local introduced diversity in the multiple-regression

TABLE 5. Summary of multiple-regression analyses of local species richness (PNAT or PINT) vs. selected independent variables at the spatial definition of "site" as a region. Table entries are regression coefficients.

\begin{tabular}{lcc}
\hline \hline $\begin{array}{c}\text { Independent } \\
\text { variable }\end{array}$ & $\begin{array}{c}\text { Dependent } \\
\text { variable } \\
=\text { PNAT }\end{array}$ & $\begin{array}{c}\text { Dependent } \\
\text { variable } \\
=\text { PINT }\end{array}$ \\
\hline SNAT R & $\ldots$ & 0.266 \\
PNAT L & $\ldots$ & -0.069 \\
SINT R & 0.278 & $-0.888^{* *}$ \\
PINT L & -0.471 & $\ldots$ \\
SAREA R & -0.686 & -0.242 \\
PFISH M & $0.302^{* *}$ & -0.033 \\
PAREA L & $0.768 \dagger$ & $0.372^{*}$ \\
HABTYPES R & -0.127 & $\ldots$ \\
PDEP L & -0.008 & -0.006 \\
PMICHAB L & $-0.008 \dagger$ & 0.002 \\
ELEV R & $\ldots$ & $\ldots$ \\
SNAT ${ }^{2}$ & $0.073^{* *}$ & -0.018 \\
Regression statistics & & \\
L:R & $0: 1$ & $1: 1$ \\
Model $R^{2}$ & $0.83^{* *}$ & $0.77 * *$ \\
Intercept & 1.24 & -0.69 \\
\hline
\end{tabular}

Notes: Variable names and regional definitions are given in Table 1. Format as in Table 4. Analyses were performed on the "partial" data set ( $N=53$ pools; see Methods: Fish and habitat sampling.). Each model was reduced from the 11 independent variables listed to the 9 variables with slope entries. Ellipses indicate that variables were not included in the final model.

$$
\dagger P<0.10, * P<0.05, * * P<0.01 \text {. }
$$



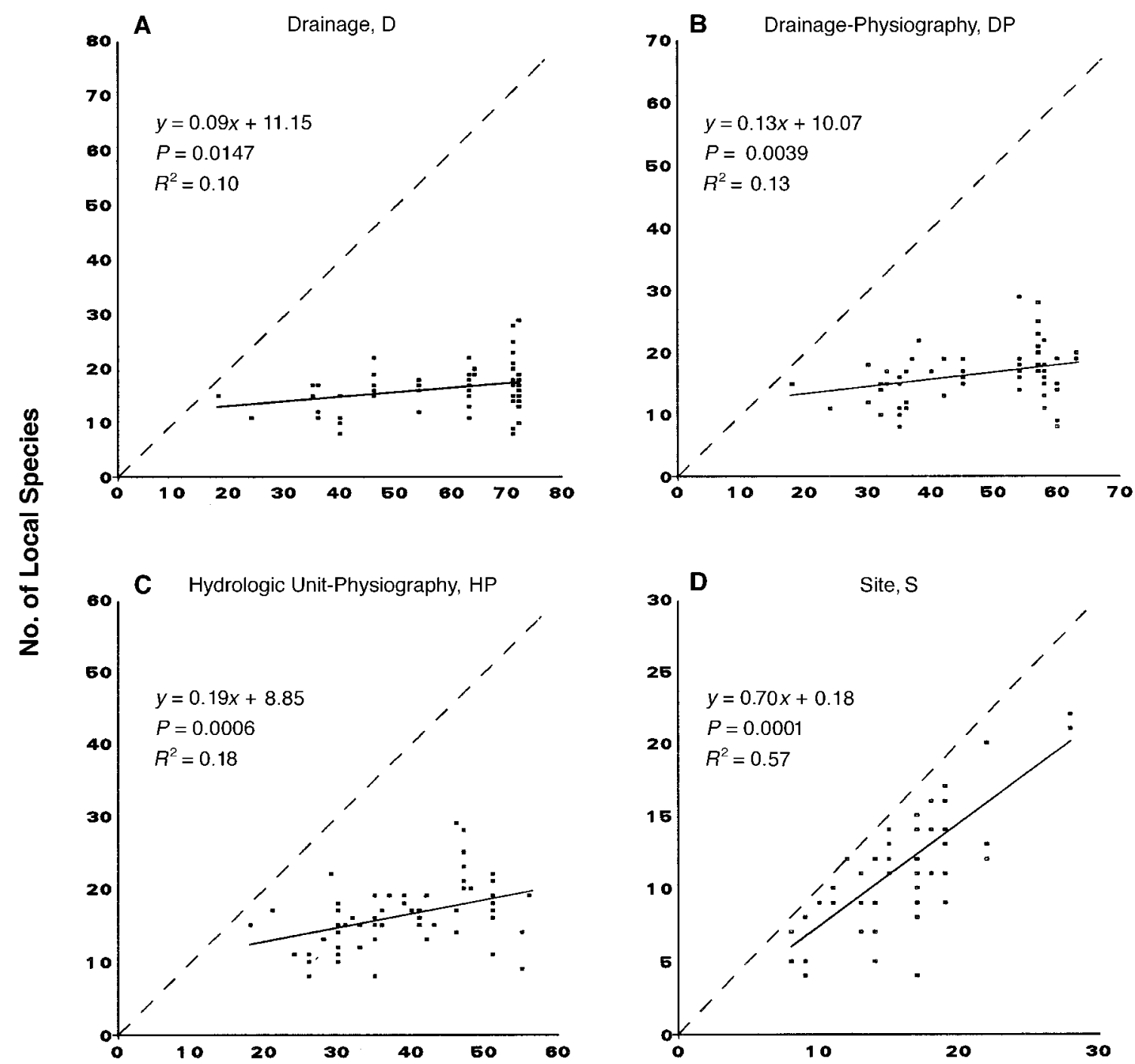

\section{No. of Regional Species}

FIG. 2. Plots of local native species richness vs. regional native species richness for four spatial definitions of "region" in Virginia (USA). Regional definitions are drainage (A), drainage-physiography (B), hydrologic unit-physiography (C), and site (D). Dashed lines have slope $=1.0$; solid lines represent the simple regression equations shown. Some plotted points represent multiple observations.

models (Tables 2, 3, 4, and 5), but the two variables were positively related in the analysis of the partial data set for DP regions (Table 3). Local native diversity did show a negative association with regional introduced diversity for D and DP regions (Tables 2 and 3).

There was no evidence of an asymptotic relationship between local introduced diversity and regional native diversity (Tables 2, 3, 4, and 5). Rather, local introduced diversity was essentially a linear function of regional introduced diversity (Fig. 3, Tables 2, 3, 4, and $5)$. Regional introduced diversity was a much better predictor of local introduced diversity than regional native diversity was of local native diversity. Overall, Prediction 4 was not confirmed.

\section{Prediction 5. Native populations are more successful} than introduced populations

Introduced diversity (regional or local) typically was much lower than native diversity. Where ranges of regional native and introduced diversity did overlap, local native diversity usually exceeded local introduced diversity, especially in D, DP, and HP regions. For example, comparing Figs. $2 \mathrm{~A}$ and $3 \mathrm{~A}$, a D region with 25 native species is expected to have $\sim 13$ native species per site, whereas a $\mathrm{D}$ region with 25 introduced species is expected to have only $\sim 5$ introduced species per site.

Introduced species did not predominate local com- 

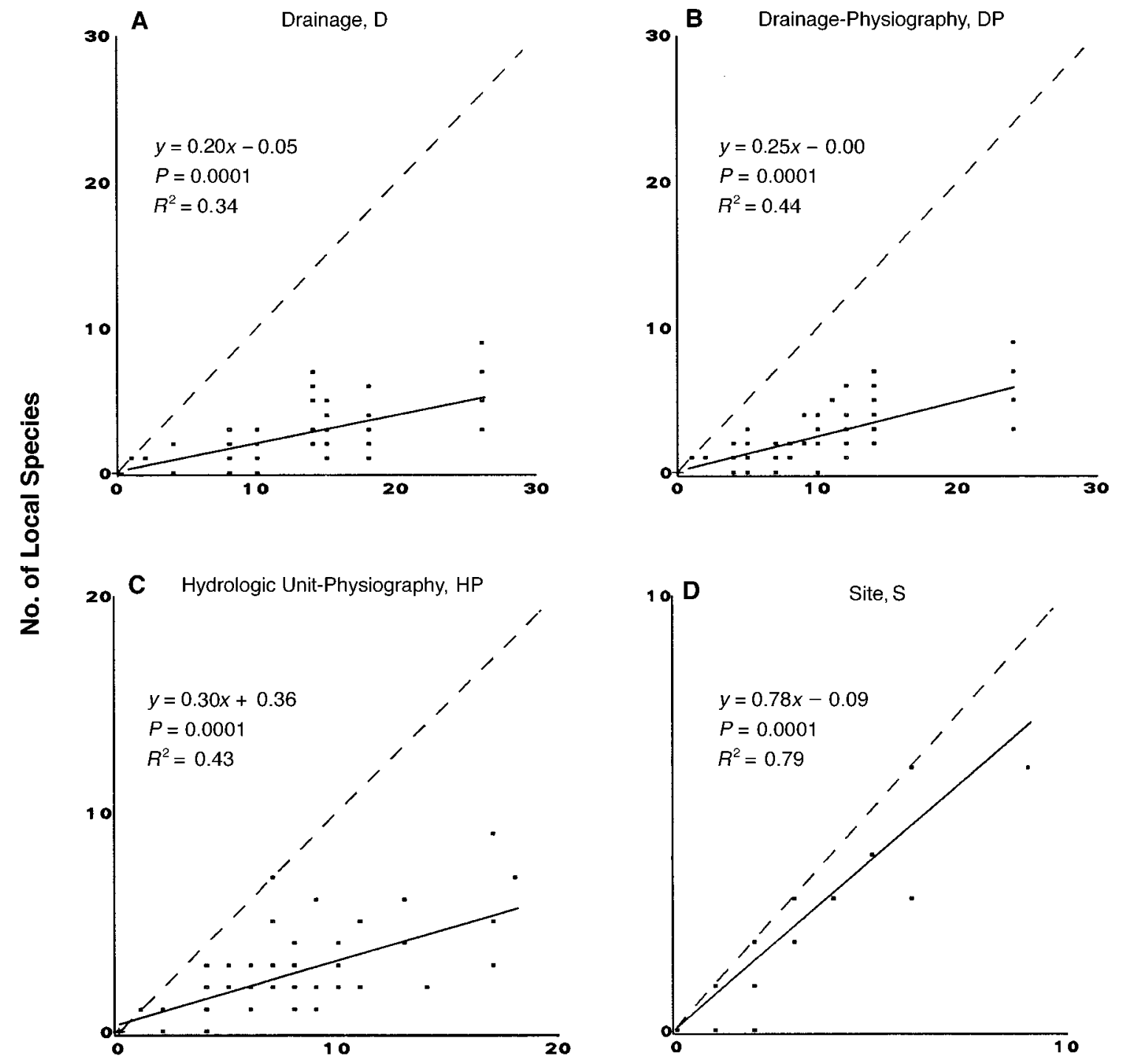

\section{No. of Regional Species}

FIG. 3. Plots of local introduced species richness vs. regional introduced species richness for four spatial definitions of "region" in Virginia (USA). Format is as in Fig. 2.

munities. The median proportion of species at a site that were introduced was 0.125 (maximum: 0.436). Introduced species represented $\geq 25 \%$ of all individuals captured at only $11(18 \%)$ sites, and never represented $>48 \%$ of the individuals at a site (median: $7 \%$ ). Introduced populations at sites typically were less abundant than co-occurring native populations (paired $t$ test, $N$ $=61$ sites $; P<0.02$ ). Overall, Prediction 5 was confirmed.

Prediction 6. Relationships between local diversity and regional factors vary with regional scale

The proportion of variance in local native diversity explained by multiple-regression models generally in- creased as regional scale decreased (e.g., from $42 \%$ in $\mathrm{D}$ regions to $80 \%$ in $\mathrm{S}$ regions; Tables 2 and 4). The greatest difference in explanatory ability occurred between models for HP and S regions, which were also the most different in spatial scale. Similar patterns were apparent in simple regression models (Fig. 2).

The factors showing significant associations with local native diversity varied considerably across regional scales. The number of significant $(P<0.05)$ variables in regression models was greatest for DP regions $(2-$ 6 variables) and least for HP regions (1-2 variables) (Tables 2, 3, 4, and 5). No variable was significant in all eight models of local native diversity, but the number of local individuals (TOTFISH, PFISH) was sig- 
nificant in seven models (Tables 2, 3, 4, and 5), thereby underscoring the influence of sampling effort on estimates of species richness. Several variables, including WAREA, HABTYPES, MAXDEP, PDEP, ELEV, RDORD, RAREA, and RNORD, were never significant predictors of local native diversity.

Although there were fewer significant $(P<0.05)$ predictors of local introduced diversity than of local native diversity, $R^{2}$ values were slightly greater for multiple-regression models of local introduced diversity, except for $\mathrm{S}$ regions (Tables 2, 3, 4, and 5). As was the case for local native diversity, models of local introduced diversity accounted for increasing proportions of variance as regional scale decreased (Tables 2 and 4; Fig. 3).

Overall, Prediction 6 was confirmed. Although some regional factors (e.g., diversity) were consistent predictors of local diversity, others appeared sporadically among regression models for various regional scales. Associations between regional factors and local diversity were scale sensitive, but the strength of association was not necessarily monotonically related to regional scale.

\section{Discussion}

\section{Local vs. regional influences}

The hypothesis that local factors dominate regulation of local diversity was not supported by our results for stream fishes in Virginia. Microhabitat diversity was the best local predictor of local native diversity, but was not a strong predictor when regions were defined as sites, and was never a useful predictor of local introduced diversity. In contrast, regional diversity consistently predicted local diversity at all regional definitions, and for both local and introduced species (Tables 2, 3, 4, and 5). Neither local nor regional factors clearly predominated in regulation of local diversity.

Influences of local factors such as habitat structure (Schlosser 1982, Angermeier and Schlosser 1989, Poff and Ward 1990) and biotic interactions (Fausch and White 1981, Power et al. 1985, Gilliam et al. 1993) on the structure of stream-fish communities have been documented extensively. Much less attention has been focused on the influences of regional and historical factors. But emerging conceptual models of community organization are hierarchical and recognize the importance of regional context to community organization (Menge and Olson 1990, Cornell and Lawton 1992, Ricklefs and Schluter 1993a). A full understanding of the organization of stream-fish communities will require a more balanced evaluation of the roles of largeand small-scale influences. Key research topics that warrant additional attention include regional consequences of local species interactions (e.g., Gilliam et al. 1993, Taylor 1996) and determinants of regional species diversity. Regional diversity is probably a complex function of biogeographical processes such as spe- ciation and dispersal (Brooks et al. 1992, Mandrak 1995), ecological constraints such as available energy (Currie 1991, Oberdorff et al. 1995), and landscape diversity. For example, among regions in Virginia, fish diversity is correlated with ranges of elevation and stream size (Warren and Angermeier, in press).

Local diversity is a subset of regional diversity. For our D, DP, and HP regions-drainage basin, physiographic province within drainage basin, and physiographic province within hydrologic unit, respectively-localities included $<50 \%$ of the regional fish species; $>70 \%$ of the species at a site typically occurred in each pool (Figs. 2 and 3). In contrast, Tonn et al. (1990) observed that $<10 \%$ of the regional fish species occurred in Wisconsin lakes. Explaining the proportion of regional species that does and does not occur locally, and why proportions vary among regions and systems, is central to understanding the relative importance of local and regional influences on community organization. Tonn et al. (1990) proposed a conceptual framework of environmental "filters," which represent the processes that sequentially reduce the regional pool of species to those occurring locally. Each filter operates at a distinctive spatiotemporal scale; examples include dispersal barriers, habitat configurations, disturbance regimes, and biotic interactions. In the context of environmental filters, analyses of local absences of regional species may reveal as much about community organization as analyses of local habitat associations or interspecific interactions. For example, a hierarchical model of assembly might be based on the proportion of species' absences attributable to key filters such as dispersal barriers or predation. Due to the large scales over which many filters operate, such analyses would likely rely on comparative rather than experimental approaches. Accurate assessment of each filter's role in community assembly would depend upon complete knowledge of the regional species pool and species' autecologies (Keddy 1992).

Environmental filters are dynamic through space and time, and may interact in complex ways, particularly in response to physical disturbance. Severe local (e.g., floods, debris flows), landscape (e.g., deforestation), or regional (e.g., glaciation) disturbances can induce species absences through changes in habitat. As successional processes restore habitat conditions, availability of refugia (Sedell et al. 1990) and colonization abilities would largely regulate local recurrence of regional species. Assembly outcome may be modified further by particular colonization sequences (Drake 1991, Gorman 1992). Community structure in newly or frequently disturbed systems typically is weakly regulated by habitat configurations (Eadie and Keast 1984, Angermeier and Schlosser 1989) or biotic interactions (Resh et al. 1988). But at later successional stages those filters should become increasingly operative. As regional scale increases, so does the number of operative filters and their cumulative influence; thus, proportionally 
fewer regional species occur locally. The marked difference in proportions of regional species occurring locally between our definitions of HP regions cf. S (individual sample site) regions illustrates the reduced effects of environmental filters at small regional scales. Most species occurring at sites also occurred in each pool because dispersal barriers and differences in habitat, disturbance, and biotic interactions were minimal among pools within a site (i.e., filters were largely inoperative).

\section{Community saturation}

The hypothesis that stream-fish communities are saturated was only partially supported. Analyses of relationships between local and regional diversity (Prediction 2) suggested saturation among native species but not among introduced species. Patterns of occurrence of introduced species (Predictions 2 and 3) provided no evidence for saturation, but patterns of fish abundance (Prediction 4) indicated that native species were better adapted than introduced species. Apparently, the communities we studied were neither completely saturated nor freely invadable.

The asymptotic relationships between local and regional native diversity for D, DP, and HP regions (Fig. 2) provided the strongest evidence for community saturation. But other explanations for asymptotes (e.g., regional heterogeneity and high local extinction rates) cannot be discounted completely. Spatial heterogeneity generally increases with region size because larger regions include wider arrays of landscape features and disturbance states. The weak asymptote we observed for HP regions relative to D and DP regions (Tables 2 and 3 ) suggests that regional heterogeneity may contribute to the asympotic patterns. However, our DP and HP regions are exceptionally homogenous relative to other regions that have been used to assess local vs. regional influences on local diversity. If DP and HP regions are too heterogeneous to interpret asymptotes clearly, the utility of asymptotes in assessing saturation is probably very limited. Without repeated samples, we could not estimate local extinction rates. However, other data from Virginia streams (P. L. Angermeier, unpublished data) indicate low species turnover among years. Overall, we believe that community saturation provides the most likely explanation for the asymptotic relationships.

The observed asymptotes must be reconciled with the pervasiveness of introduced species, the lack of an inverse relationship between native and introduced local diversity, and the lack of an asymptotic relationship between local and regional introduced diversity. Each of these patterns is inconsistent with saturation, but important gaps in our understanding preclude clear interpretations. First, frequencies of unsuccessful introductions are unknown, yet crucial to measuring invadability. Given repeated attempts, all fish communities may be invadable (Moyle and Light 1996). High in- cidences of introduced species could reflect repeated introductions rather than low resistance to invasion. Historical records for Virginia indicate that multiple introductions often were required to establish game fishes (Jenkins and Burkhead 1994). Furthermore, continual stocking (official and unofficial) of the non-native fishes already established would prolong their local and regional persistence. A second major unknown is the ecological response of invaded communities; filling this gap would require precise knowledge of pre- and post-invasion community structure. Our analytical approach probably would not detect small changes in community structure, such as shifts in proportional abundance or loss of a few species.

Finally, the extent to which stream environments (and the attendant filters) have been modified by intensive human use over the last two centuries is largely unknown. The rapid and dramatic changes in North American landscapes (e.g., Whitney 1994) are expected to alter species' distributions. Retrospective analyses of fish extirpations in Virginia indicate that environmental degradation is complex and pervasive (Angermeier 1995). Our sites exhibited minimal impact but they certainly do not represent the conditions in which native fishes evolved. Introduced fishes typically do best in modified systems (Herbold and Moyle 1986, Ross 1991, Courtenay and Moyle 1996). Their widespread occurrence in Virginia may, in part, reflect preadaptation to pervasive anthropogenic impacts such as elevated temperatures and fine-sediment loads.

Our understanding of community saturation would benefit from more sophisticated analyses of the function of invaders. For example, introduced fishes that are small herbivores or insectivores tend to have less impact on native communities than do large piscivores (Courtenay and Moyle 1996). Theoretical models of community assembly suggest that communities with high connectance are difficult to invade, but increases in the number of predators can enhance the invasion success of new prey species (Pimm 1989). These findings may help explain why we found evidence for saturation among native fishes but widespread invasion by introduced fishes. Many introduced fish species in Virginia streams are piscivorous as adults; $47 \%$ are in the families Ictaluridae, Esocidae, Salmonidae, Percichthyidae, or Centrarchidae (Jenkins and Burkhead 1994). Even if historical communities were saturated, additions of piscivores may have shifted the population dynamics of prey fishes enough to allow additional introduced species to invade without driving native species to regional extinction. Invasion resistance would have been especially low in regions with the fewest native species (e.g., Atlantic-slope drainages), where the greatest numbers of introduced species now occur (Jenkins and Burkhead 1994). Thus, relationships between local and regional native diversity could still be asymptotic (i.e., reflect saturation) even though many species have been introduced. 
Given the wide variation in disturbance regime (e.g., Poff and Ward 1989) and phylogenetic history experienced by fish communities, it is unlikely that all are near saturation. Eastern North America supports the most diverse temperate fish fauna in the world (Page and Burr 1991). Local saturation seems more likely here than in less speciose regions such as western North America (Moyle and Herbold 1987) or in regions with frequent severe disturbances (Hugueny and Paugy 1995). Strong competitive interactions, the expected consequences of saturation, are important in the organization of some stream-fish communities (e.g., Fausch and White 1981, Baltz et al. 1982, Taylor 1996) but probably do not predominate enough to indicate that communities throughout regions are continuously saturated. Community saturation is more likely to occur in lakes (e.g., Tonn et al. 1990), where severe disturbances typically are less frequent than in streams, and competition among fishes often is intense (e.g., Mittelbach 1988, Robinson and Wilson 1994). However, Griffiths (1997) found little evidence of saturation in fish communities of North American lakes, perhaps because most of the lakes he analyzed occurred considerably north of regions with high fish-species densities (see McAllister et al. 1986). Because saturation is partly a function of dispersal ability, we also expect major taxa within a region to exhibit different probabilities of saturation. For example, communities of aquatic insects, fishes, and aquatic mollusks might exhibit decreasing degrees of saturation.

\section{Defining appropriate regions}

The hypothesis that regional "effects" on local diversity are scale dependent was supported by our results. As spatial scale decreased from D to DP to HP regions, regression models and individual factors varied considerably in their ability to account for variation in local diversity even though that variation remained constant. Shifts in associations between local diversity and regression variables probably reflected subtle shifts in the dispersion of values taken by variables (ranges were constant for most variables). The variance of ecological variables typically changes over different scales of measurement (Wiens 1989). Conversely, the lack of association between many of our independent variables (e.g., WAREA, ELEV) and local diversity probably reflects our restrictive selection of sites (i.e., little variation) rather than the unimportance of those factors to community organization.

Clear interpretation of regional influences on local diversity requires careful definition of regions. Because any regional definition is somewhat arbitrary, the local-regional dichotomy is really a continuum of dichotomies; each can provide insight into a distinctive set of organizing processes (Ricklefs and Schluter $1993 a$ ). The scale dependence of many regional factors dictates that comparative analyses at multiple regional scales is the best strategy for gaining a complete un- derstanding of regional influences. As regional definitions get larger, the number of operative environmental filters increases, but regional influences on local diversity probably become less tightly linked to each locality. The tendency for our regression models for D regions to have the least explanatory power is consistent with this decoupling of local and large regional scales.

Appropriate regional definitions should reflect important ecological and evolutionary processes such as habitat selection, disturbance, dispersal, and gene flow, which vary in scale among taxa. Large heterogeneous regions (e.g., continents) and regions too small to accommodate viable populations generally are inappropriate for evaluating local and regional influences on local diversity. Although of heuristic value in examining effects of regional scale, our sites were inappropriate regions in evolutionary or ecological contexts. Our DP and HP regions were probably the most appropriate for comparing local and regional influences because streams within each region shared a common history, had similar habitat, and were accessible to all regional species over ecological timeframes.

\section{Conclusions}

Understanding the organization of complex communities requires multiple analytical approaches, including comparisons of local and regional influences, and experimental study of specific mechanisms. Clarifying regional influences, which generally are not amenable to experimentation, may be aided by defining multiple regional scales. Knowledge of regional context should help refine hypotheses and interpretations regarding community assembly and organization (Brooks and McLennan 1993). For example, assessing community response to disturbance on the basis of changes in species composition requires knowledge of life-history strategies and regional diversity, which are closely tied to phylogenetic history. As ecologists continue to sort out the roles of the many processes involved in community organization, local vs. regional contrasts will become increasingly important in revealing how and where those processes operate.

\section{ACKNOWLEDGMENTS}

The Virginia Cooperative Fish and Wildlife Research Unit is jointly supported by the United States Geological Survey, Virginia Department of Game and Inland Fisheries, and Virginia Polytechnic Institute and State University. Fieldwork was supported by the Virginia Department of Game and Inland Fisheries. Most analyses were supported by the National Biological Service, National Fisheries Research Center-Leetown. We are grateful to R. A. Smogor for assisting with fieldwork and selection of the fish collections, to J. B. Birch for statistical advice, and to N. L. Poff, M. L. Warren, Jr., and two anonymous reviwers for helpful comments on an earlier draft.

\section{Literature Cited}

Angermeier, P. L. 1995. Ecological attributes of extinctionprone species: loss of freshwater fishes of Virginia. Conservation Biology 9:143-158. 
Angermeier, P. L., and I. J. Schlosser. 1989. Species-area relationships for stream fishes. Ecology 70:1450-1462.

Angermeier, P. L., and R. A. Smogor. 1995. Estimating number of species and relative abundances in stream-fish communities: effects of sampling effort and discontinuous spatial distributions. Canadian Journal of Fisheries and Aquatic Sciences 52:936-949.

Angermeier, P. L., R. A. Smogor, and S. D. Steele. 1991. An electric seine for collecting fish in streams. North American Journal of Fisheries Management 11:352-357.

Baltz, D. M., P. B. Moyle, and N. J. Knight. 1982. Competitive interactions between benthic stream fishes, riffle sculpin, Cottus gulosus, and speckled dace, Rhinichthys osculus. Canadian Journal of Fisheries and Aquatic Sciences 39:1502-1511.

Bayley, P. B., R. W. Larimore, and D. C. Dowling. 1989 Electric seine as a fish-sampling gear in streams. Transactions of the American Fisheries Society 118:447-453.

Brooks, D. R., R. L. Mayden, and D. A. McLennan. 1992. Phylogeny and biodiversity: conserving our evolutionary legacy. Trends in Ecology and Evolution 7:55-59.

Brooks, D. R., and D. A. McLennan. 1993. Historical ecology: examining phylogenetic components of community evolution. Pages 267-280 in R. E. Ricklefs and D. Schluter, editors. Species diversity in ecological communities: historical and geographical perspectives. University of Chicago Press, Chicago, Illinois, USA.

Case, T. J. 1991. Invasion resistance, species build-up and community collapse in metapopulation models with interspecies competition. Biological Journal of the Linnean Society 42:239-266.

Caswell, H., and J. E. Cohen. 1993. Local and regional regulation of species-area relations: a patch-occupancy model. Pages 99-107 in R. E. Ricklefs and D. Schluter, editors. Species diversity in ecological communities: historical and geographical perspectives. University of Chicago Press, Chicago, Illinois, USA.

Cornell, H. V. 1993. Unsaturated patterns in species assemblages: the role of regional processes in setting local species richness. Pages 243-252 in R. E. Ricklefs an D. Schluter, editors. Species diversity in ecological communities: historical and geographical perspectives. University of Chicago Press, Chicago, Illinois, USA.

Cornell, H. V., and J. H. Lawton. 1992. Species interactions, local and regional processes, and limits to the richness of ecological communities: a theoretical perspective. Journal of Animal Ecology 61:1-12.

Courtenay, W. R., Jr., and P. B. Moyle. 1996. Biodiversity, fishes, and the introduction paradigm. Pages 239-252 in R. C. Szaro and D. W. Johnston, editors. Biodiversity in managed landscapes. Oxford University Press, New York, New York, USA.

Currie, D. J. 1991. Energy and large-scale patterns of animaland plant-species richness. American Naturalist 137:2749.

Drake, J. A. 1991. Community-assembly mechanics and the structure of an experimental species ensemble. American Naturalist 137:1-26.

Eadie, J. M., and A. Keast. 1984. Resource heterogeneity and fish species diversity in lakes. Canadian Journal of Zoology 62:1689-1695.

Fausch, K. D., and R. J. White. 1981. Competition between brook trout (Salvelinus fontinalis) and brown trout (Salmo trutta) for positions in a Michigan stream. Canadian Journal of Fisheries and Aquatic Sciences 38:1220-1227.

Fenneman, N. M. 1946. Physical divisions of the United States. Map. (Scale 1:7,000,000) U.S. Geological Survey, Reston, Virginia, USA.

Flather, C. H., L. A. Joyce, and C. A. Bloomgarden. 1994. Species endangerment patterns in the United States. Gen- eral Technical Report RM-241. United States Forest Service, Fort Collins, Colorado, USA.

Gilliam, J. F., D. F. Fraser, and M. Alkins-Koo. 1993. Structure of a tropical fish community: a role for biotic interactions. Ecology 74:1856-1870.

Gorman, O. T. 1986. Assemblage organization of stream fishes: the effect of rivers on adventitious streams. American Naturalist 128:611-616.

1992. Evolutionary ecology and historical ecology: assembly, structure, and organization of stream fish communities. Pages 659-688 in R. L. Mayden, editor. Systematics, historical ecology, and North American freshwater fishes. Stanford University Press, Stanford, California, USA.

Griffiths, D. 1997. Local and regional species richness in North American lacustrine fish. Journal of Animal Ecology 66:49-56.

Herbold, B., and P. B. Moyle. 1986. Introduced species and vacant niches. American Naturalist 128:751-760.

Hinch, S. G., N. C. Collins, and H. H. Harvey. 1991. Relative abundance of littoral zone fishes: biotic interactions, abiotic factors, and postglacial colonization. Ecology 72:13141324.

Hocutt, C. H., and E. O Wiley, editors. 1986. The zoogeography of North American freshwater fishes. John Wiley \& Sons, New York, New York, USA.

Hugueny, B., and D. Paugy. 1995. Unsaturated fish communities in African rivers. American Naturalist 146:162169.

Iman, R. L., and W. J. Conover. 1979. The use of the rank transform in regression. Technometrics 21:499-509.

Jackson, D. A., and H. H. Harvey. 1989. Biogeographic associations in fish assemblages: local vs. regional process. Ecology 70:1472-1484

Jenkins, R. E., and N. M. Burkhead. 1994. Freshwater fishes of Virginia. American Fisheries Society, Bethesda, Maryland, USA.

Keddy, P. A. 1992. Assembly and response rules: two goals for predictive community ecology. Journal of Vegetation Science 3:157-164.

Krebs, C. J. 1989. Ecological methodology. Harper \& Row, New York, New York, USA.

Lee, D. S., C. R. Gilbert, C. H. Hocutt, R. E. Jenkins, D. E. McAllister, and J. R. Stauffer, Jr. 1980. Atlas of North American freshwater fishes. North Carolina State Museum of Natural History, Raleigh, North Carolina, USA.

Mahon, R. 1984. Divergent structure in fish taxocenes of north temperature streams. Canadian Journal of Fisheries and Aquatic Sciences 41:330-350.

Mandrak, N. E. 1995. Biogeographic patterns of fish species richness in Ontario lakes in relation to historical and environmental factors. Canadian Journal of Fisheries and Aquatic Sciences 52:1462-1474.

Mayden, R., editor. 1992. Systematics, historical ecology, and North American freshwater fishes. Stanford University Press, Stanford, California, USA.

McAllister, D. E., S. P. Platania, F. W. Schueler, M. E. Baldwin, and D. S. Lee. 1986. Icthyofaunal patterns on a geographic grid. Pages 17-51 in C. H. Hocutt and E. O. Wiley, editors. The zoogeography of North American freshwater fishes. John Wiley \& Sons, New York, New York, USA.

Menge, B. A., and A. M. Olson. 1990. Role of scale and environmental factors in regulation of community structure. Trends in Ecology and Evolution 5:52-57.

Mittelbach, G. G. 1988. Competition among refuging sunfishes and effects of fish density on littoral zone invertebrates. Ecology 69:614-623.

Moyle, P. B., and B. Herbold. 1987. Life-history patterns and community structure in stream fishes of western North America: comparisons with eastern North America and Eu- 
rope. Pages 25-32 in W. J. Matthews and D. C. Heins, editors. Community and evolutionary ecology of North American stream fishes. University of Oklahoma Press, Norman, Oklahoma, USA.

Moyle, P. B., and T. Light. 1996. Fish invasions in California: Do abiotic factors determine success? Ecology 77:16661670.

Oberdorff, T., J.-F. Guegan, and B. Hugueny. 1995. Global scales of fish species richness in rivers. Ecography 18:345352.

Osborne, L. L., and M. J. Wiley. 1992. Influence of tributary spatial position on the structure of warmwater fish communities. Canadian Journal of Fisheries and Aquatic Sciences 49:671-681.

Page, L. M., and B. M. Burr. 1991. A field guide to freshwater fishes: North America north of Mexico. Houghton Mifflin, Boston, Massachusetts, USA.

Pimm, S. L. 1989. Theories of predicting success and impact of introduced species. Pages 351-367 in J. A. Drake, H. A. Mooney, F. diCastri, R. H. Groves, F. J Kruger, M. Rejmanek, and M. Williamson, editors. Biological invasions: a global perspective. John Wiley \& Sons, New York, New York, USA.

Poff, N. L., and J. V. Ward. 1989. Implications of streamflow variability and predictability for lotic community structure: a regional analysis of streamflow patterns. Canadian Journal of Fisheries and Aquatic Sciences 46:1805-1818.

Poff, N. L., and J. V. Ward. 1990. Physical habitat template of lotic systems: recovery in the context of historical pattern of spatiotemporal heterogeneity. Environmental Management 14:629-645.

Power, M. E., M. J. Matthews, and A. J. Stewart. 1985. Grazing minnows, piscivorous bass, and stream algae: dynamics of a strong interaction. Ecology 66:1448-1436.

Resh, V. H., A. V. Brown, A. P. Covich, M. E. Gurtz, H. W. Li, G. W. Minshall, S. R. Reice, A. L. Sheldon, J. B. Wallace, and R. C. Wissmar. 1988. The role of disturbance in stream ecology. Journal of the North American Benthological Society 7:433-455.

Ricklefs, R. E. 1987. Community diversity: relative roles of local and regional processes. Science 235:167-171.

Ricklefs, R. E., and D. Schluter. 1993a. Species diversity: regional and historical influences. Pages 350-363 in R. E. Ricklefs and D. Schluter, editors. Species diversity in ecological communities: historical and geographical perspectives. University of Chicago Press, Chicago, Ilinois, USA

Ricklefs, R. E., and D. Schluter, editors. 1993b. Species diversity in ecological communities: historical and geographical perspectives. University of Chicago Press, Chicago, Illinois, USA.

Robinson, B. W., and D. S. Wilson. 1994. Character release and displacement in fishes: a neglected literature. American Naturalist 144:596-627.

Ross, S. T. 1991. Mechanisms structuring stream fish assemblages: are there lessons from introduced species? Environmental Biology of Fishes 30:359-368.

Schlosser, I. J. 1982. Fish community structure and function along two habitat gradients in a headwater stream. Ecological Monographs 52:395-414.

Schluter, D., and R. E. Ricklefs. 1993. Species diversity: an introduction to the problem. Pages 1-10 in R. E. Ricklefs and D. Schluter, editors. Species diversity in ecological communities: historical and geographical perspectives. University of Chicago Press, Chicago, Illinois, USA.

Sedell, J. R., G. H. Reeves, F. R. Hauer, J. A. Stanford, and C. P. Hawkins. 1990. Role of refugia in recovery from disturbances: modern fragmented and disconnected river systems. Environmental Management 14:711-724.

Shulman, R. S. 1992. Statistics in plain English; with computer applications. Van Nostrand Reinhold, New York, New York, USA.

Simberloff, D. S. 1970. Taxonomic diversity of island biotas. Evolution 24:23-47.

Swanson, F. J., T. K. Kratz, N. Caine, and R. G. Woodmansee. 1988. Landform effects on ecosystem patterns and processes. BioScience 38:92-98.

Taylor, C. M. 1996. Abundance and distribution within a guild of benthic stream fishes: local processes and regional patterns. Freshwater Biology 36:385-396.

Tonn, W. M., J. J. Magnuson, M. Rask, and J. Toivonen. 1990. Intercontinental comparison of small-lake fish assemblages: the balance between local and regional processes. American Naturalist 136:345-375.

USGS [United State Geological Survey]. 1980. Hydrologic unit map-1974; state of Virginia. United States Geological Survey, Reston, Virginia, USA.

Warren, M. L., Jr., and P. L. Angermeier. In press. Protocols for assessing aquatic biodiversity: GIS applications in Virginia. Proceedings of the 4th National U.S. Fish and Wildlife Service GIS Workshop. U.S. Fish and Wildlife Service, Washington, D.C., USA.

Whitney, G. G. 1994. From coastal wilderness to fruited plain: a history of environmental change in temperate North America from 1500 to the present. Cambridge University Press, Cambridge, UK.

Wiens, J. A. 1989. Spatial scaling in ecology. Functional Ecology 3:385-397.

Williams, J. E., J. E. Johnson, D. A. Hendrickson, S. Contreras-Balderas, J. D. Williams, M. Navarro-Mendoza, D. E. McAllister, and J. E. Deacon. 1989. Fishes of North America endangered, threatened, or of special concern: 1989. Fisheries (Bethesda) 14(6):2-20. 


\section{APPENDIX}

Physical descriptors (means, standard deviations, minima, maxima, and number of observations) of stream localities in Virginia, USA, summarized over three regional definitions (D, DP, HP). Regional definitions and variable names are described in Table 1. Summary statistics for most variables were computed from the "full" (61-site) data set; those with a superscript "P" were computed from the "partial" (40-site) data set (see Methods: Fish and habitat sampling and Correlates of species richness for explanation).

\begin{tabular}{|c|c|c|c|c|c|c|}
\hline Variable & $\begin{array}{l}\text { Regional } \\
\text { definition }\end{array}$ & $\bar{X}$ & $1 \mathrm{SD}$ & Min. & Max. & $N$ \\
\hline SAREA $\left(\mathrm{m}^{2}\right)$ & $\dagger$ & 1019 & 277 & 356 & 3167 & 61 \\
\hline WAREA $\left(\mathrm{km}^{2}\right)$ & $\dagger$ & 81 & 63 & 13 & 363 & 61 \\
\hline PAREA $\left(\mathrm{m}^{2}\right)$ & $\dagger$ & 276 & 265 & 55 & 1806 & 62 \\
\hline HABTYPES & $\dagger$ & 2.2 & 0.1 & 1 & 3 & 61 \\
\hline MAXDEP $(\mathrm{cm})$ & $\dagger$ & 75 & 26 & 30 & 125 & 61 \\
\hline $\operatorname{PDEP}(\mathrm{cm})$ & $\dagger$ & 70 & 25 & 11 & 125 & 62 \\
\hline $\mathrm{MICHAB}^{\mathrm{P}}$ & $\dagger$ & 40.5 & 12.3 & 20 & 78 & 40 \\
\hline $\mathrm{PMICHAB}^{\mathrm{P}}$ & $\dagger$ & 20.0 & 5.4 & 4 & 30 & 53 \\
\hline ELEV (m) & $\dagger$ & 195 & 178 & 2 & 681 & 61 \\
\hline RDORD (km) & $\dagger$ & 7.8 & 2.3 & 0.2 & 40 & 61 \\
\hline \multirow[t]{3}{*}{ RAREA $\left(\mathrm{km}^{2}\right)$} & $\mathrm{D}$ & 9794 & 7631 & 1413 & 26333 & 10 \\
\hline & DP & 4372 & 3484 & 322 & 13028 & 19 \\
\hline & HP & 2108 & 1065 & 322 & 5352 & 32 \\
\hline \multirow[t]{3}{*}{ RNORD } & $\mathrm{D}$ & 6.8 & 1.0 & 4 & 8 & 10 \\
\hline & DP & 6.3 & 1.1 & 4 & 8 & 19 \\
\hline & HP & 6.2 & 1.0 & 4 & 7 & 32 \\
\hline
\end{tabular}

$\dagger$ Statistics are constant among regional definitions. 